\title{
REVIEW
}

\section{Insights into DNA-drug interactions in the era of omics}

\section{José Portugal*}

Instituto de Diagnóstico Ambiental y Estudios del Agua, CSIC, Barcelona, Spain

* correspondence to:

Dr. José Portugal

IDAEA-CSIC

Jordi Girona, 18-26

E-08034 Barcelona, Spain

Phone: +34934006128

Fax: +34 932045904

E-mail: jose.portugal@idaea.csic.es

Funding Information: Work in the author's laboratory is supported by grant RTI2018096175-B-I00 from the Spanish Ministry of Science, Innovation and Universities, and by the Generalitat de Catalunya (2017SGR902). 


\begin{abstract}
Despite the rise of sophisticated new targeting strategies in cancer chemotherapy, many classic DNA-binding drugs remain on the front line of the therapy against cancer. Based on examples primarily from the author's laboratory, this paper reviews the capabilities of several DNAbinding drugs to alter gene expression. Research is ongoing about the molecular bases of the inhibition of gene expression and how alteration of the cellular transcriptome can commit cancer cells to die. The development of a variety of omic techniques allows us to gain insights into the effect of antitumor drugs. Genome-wide approaches provide unbiased genomic data that can facilitate a deeper understanding of the cellular response to DNA-binding drugs. Moreover, the results of large-scale genomic studies are gathered in publicly available databases that can be used in developing precision medicine in cancer treatment.
\end{abstract}

Keywords: cell death, DNA-drug interactions, genomics, transcription, transcription factors.

\title{
1. INTRODUCTION
}

Back in 1981, Michael Waring wrote on DNA-binding antitumor drugs: “... correlations have been found between efficacy in vivo, inhibitory activity towards RNA polymerase and the rate constants for the dissociation of the ligand-DNA complex. There remains a gap, however, between understanding the molecular bases of inhibition of RNA synthesis and relating that biochemical blockage to cell death". ${ }^{[1]}$ Significant advances have occurred since these words were written, providing new tools and insights to address Michael's prescient concern. In this review, I describe some of them, underlining the role played by gene expression and its inhibition by DNA-binding drugs, as well as the utility of genomic approaches to understand the mechanisms of action and effects of antitumor agents on the fate of cancer cells.

It is beyond any doubt that the antitumor therapeutic effects of several DNA-binding antitumor drugs can be rationalized through their effects on gene expression and thus to the inhibition of RNA synthesis. ${ }^{[2-6]}$ Some of those drugs have been used from the earliest chemotherapy and they continue in clinical use, ${ }^{[1,7]}$ which boosts the interest in gaining more detailed information on their mechanism of action. ${ }^{[6-8]}$ In this context, many DNA-binding drugs have been evaluated, hoping to learn the rules for targeting specific DNA sequences and for controlling gene expression in cancer cells. ${ }^{[7,9]}$ In recent years, the understanding of how antitumor agents commit cells to die has advanced, even though the cause of the killing effect is not fully understood. ${ }^{[10]}$

Despite our growing understanding of the altered gene expression in cancer cells, ${ }^{[6,11]}$ there are only a few examples of compounds in clinical use that have been developed to target 
transcription. ${ }^{[3,6]}$ The clinical success of many first-line antitumor agents, such as the anthracyclines or actinomycin D, can, to some extent, be assigned to their ability to inhibit gene expression by direct interference with DNA-protein interactions. ${ }^{[9,12]}$ Monitoring genomewide changes in gene expression, which can lead to drug-induced cell death, provides global insights into changes in the transcriptome that can deliver useful details for successful cancer treatment.

\section{TRANSCRIPTION CAN BE ALTERED BY DNA-DRUG INTERACTIONS}

Among other mechanisms of action, antitumor drugs can modulate gene expression through their inhibition of DNA-transcription factor interactions. This has raised considerable interest in searching for drugs targeted to sequences specifically recognized by certain transcription factors, ${ }^{[2,4,6,9]}$ with special emphasis on those that are overexpressed in cancer cells. Besides, tumor cells can depend on increased transcription levels regulated by gene enhancers. ${ }^{[13]}$ Those cells might be more sensitive to both promoter and enhancer inhibition.

Although targeting transcription is often viewed as problematic, there are compelling reasons for considering it a field of therapeutic interest because transcription factors and RNA synthesis are vulnerable key points in almost any cancer cell. ${ }^{[3-4,6,11]}$ Super-enhancers, which encompass multiple enhancers that contain putative transcription factor binding sites, are being explored as suitable antitumor targets. ${ }^{[14]}$ Furthermore, DNA topoisomerases play important roles in transcription, in which they deal with the DNA supercoiling that accumulates ahead and behind the transcription machinery, and they are therapeutic targets of several anticancer drugs. ${ }^{[15]}$ Among them, type IIA topoisomerases are remarkable antitumor therapeutic targets. ${ }^{[16]}$

Timely reviews have been published about the effects of DNA-binding drugs on transcription and transcription factor interactions. ${ }^{[2-3,6]}$ In the following paragraphs, I present some paradigmatic examples of DNA-binding drugs that modify the binding of certain transcription factors to gene promoters to alter gene expression and commit tumor cells to die. No attempt will be made to survey the vast bibliography on DNA-drug interactions and the effects of drugs on transcription.

\subsection{Anthracyclines and Bisanthracyclines}

Doxorubicin (Adriamycin) (Figure 1) and daunorubicin were the first anthracyclines in clinical use, and they are still among the most effective anticancer agents against a number of human cancers. ${ }^{[17]}$ Their toxic side effects, such as chronic cardiotoxicity and acute myelosuppression, have fueled the search for less toxic derivatives. ${ }^{[17]}$ The anthracyclines bind tightly to DNA by intercalating preferentially at $5^{\prime}-\mathrm{CG}-3$ ' sites, ${ }^{[18]}$ and they inhibit RNA polymerases of various 
sources. ${ }^{[1]}$ DNA and topoisomerase II are primary cellular targets for anthracyclines, yet the in vivo mechanism of action seems to be pleiotropic. ${ }^{[6]}$ The synthetic anthracycline mitoxantrone (a substituted aglyconic anthraquinone), frequently used in the treatment of a variety of cancers, is firmly established as a topoisomerase II $\beta$ poison. ${ }^{[19]}$

Hypoxia is a common characteristic of solid tumors. It can increase the activity of the HIF1 transcription factor. Overexpression of HIF-1 has been observed in diverse human cancers, which produces the transcription of genes like VEGF (vascular endothelial growth factor), increasing local vascularization and systemic oxygen transport. ${ }^{[20]}$ Anthracyclines have been explored as drugs for abrogating the HIF-1 activity. Doxorubicin and daunorubicin inhibit HIF1-mediated gene transcription by blocking the binding of HIF-1 to DNA. ${ }^{[21]}$ These drugs efficiently inhibit the transcription of a HIF-1-dependent reporter gene in mice bearing human tumor xenografts, as well as the transcription of the endogenous HIF-1 target genes. ${ }^{[21]}$ Moreover, doxorubicin can inhibit transcription activated by other factors like E2F1 and Sp1. ${ }^{[22]}$

Novel bisanthracyclines have been designed and synthetized, based on the structure of a daunorubicin-DNA complex. These bis-intercalating compounds combine the intercalation moiety with groove binding motifs, resulting in both higher DNA-binding affinity and sequence discrimination. ${ }^{[23-24]}$ Bisanthracycline WP631 consists of two daunorubicin molecules connected by a $p$-xylenyl linker (Figure 1). The structurally related bisanthracycline WP762 is composed of two daunorubicin monomers connected via an $m$-xylenyl linker. ${ }^{[25]}$ It binds to DNA with a picomolar binding affinity. ${ }^{[25]}$ Both bis-intercalating anthracyclines reduce the viability of various human cancer cell lines, ${ }^{[23,25-26]}$ but, to date, they have not been developed clinically.

WP631 inhibits in vitro both the basal and Sp1-activated transcription from a strong adenovirus promoter. ${ }^{[27]}$ The effects of WP631 on Sp1-activated transcription have also been evaluated in human Jurkat $\mathrm{T}$ lymphocytes transfected with DNA plasmids bearing a reporter gene under the control of the human GLUT1 (glucose transporter1) gene promoter. ${ }^{[28]}$ GLUT1 is highly expressed in proliferating cells, and Sp1 strongly transactivates the GLUT1 promoter. Nanomolar concentrations of WP631 inhibit the expression of GLUT1 promoters driven by the cellular transcription machinery. WP631 and Sp1 and Sp3 transcription factors seem to compete for DNA-binding, whereas the presence of WP631 significantly inhibits the transcription of GLUT1. ${ }^{[28]}$ This bisanthracycline specifically inhibits Sp1-activated transcription, and it competes with Sp3 binding to inhibit gene transcription. ${ }^{[12,28]}$ Furthermore, exposing Jurkat T lymphocytes to nanomolar concentrations of WP631 results in cell death that 
is preceded by changes in the expression of several genes, including oncogenes and tumor suppressor genes, ${ }^{[29]}$ (see also Figure $2 \mathrm{~A}$ and Table 1 ).

WP631 also down-regulates the expression of the multidrug resistance gene (MRP-1) by inhibiting the Sp1-activated transcription. ${ }^{[30]}$ Besides, WP631 has been used to identify Sp1 as a regulating element for the urokinase-type plasminogen activator receptor gene $(u P A R)$ in colon cancer cells. ${ }^{[31]}$

\subsection{Actinomycin D}

Actinomycin D (Dactinomycin) is a polypeptide antibiotic (Figure 1) used for treating childhood tumors, pancreatic cancer, and advanced gynecological cancers. ${ }^{[32-33]}$ Actinomycin D intercalates its chromophore between 5'-GC-3' DNA base pairs, ${ }^{[34]}$ yet not all the 5'-GC-3' sites are equivalent targets for this compound. ${ }^{[35]}$ Actinomycin D antitumor activity is related to its capacity for inhibiting RNA polymerases and decrease transcription. It is used as a tool for producing rapid and specific inhibition of RNA synthesis in studies on the metabolism of messenger RNA. ${ }^{[1,36]}$

Actinomycin A is a strong inhibitor of Sp1-DNA interactions, ${ }^{[2]}$ and it decreases the expression of the vascular endothelial growth factor $(V E G F)$ gene in non-small cell lung cancer. ${ }^{[37]}$ Hypoxia-driven VEGF expression is Sp1-dependent, with actinomycin downregulating Sp1 binding to the gene promoter. ${ }^{[37]}$ Actinomycin D can inhibit the formation of various DNA-protein complexes in the $\mathrm{P} 1$ and $\mathrm{P} 2$ promoter regions of the $c$-myc gene. ${ }^{[38]} \mathrm{In}$ particular, the binding of actinomycin D to the P1 promoter prevents the binding of Sp1, reducing gene expression. ${ }^{[38]}$

\subsection{Echinomycin}

Echinomycin, a quinoxaline antibiotic (Figure 1), binds to DNA at CG-rich sequences. ${ }^{[39-40]}$ It was the first characterized natural bis-intercalating compound. ${ }^{[39-40]}$ Echinomycin inhibits the binding of the HIF-1 transcription factor to consensus DNA sequences and the expression of the corresponding target genes. ${ }^{[41-42]}$ In U251 glioblastoma hypoxic cells (hypoxia was mimicked by treating cells with the iron chelator deferoxamine), echinomycin down-regulates almost every gene induced by hypoxia, largely genes related to the regulation of transcription, ${ }^{[41]}$ (see also Figure 2B and Table 2). It also inhibits HIF-1 activity under hypoxic conditions in human HepG2 hepatoma cells, but the effects are not specific to this transcription factor, given that the binding of AP-1 and c-myc are also disturbed. ${ }^{[43]}$ Echinomycin increases HIF-1 and Sp1 activities under normoxia. ${ }^{[43]}$ Furthermore, it inhibits adipogenesis in 3T3-L1 white adipose tissue cells in a HIF-independent way. ${ }^{[44]}$ In this case, the CCAAT/enhancerprotein $\beta$ transcription factor is a key target of echinomycin. ${ }^{[44]}$ 
In a mouse model of relapsed acute myeloid leukemia (AML), echinomycin protects mice against relapsed AML without impairing normal hematopoiesis. ${ }^{[45]}$ Echinomycin specifically halts the cell cycle before the onset of transcription, and it could exert antiproliferative effects by inhibition of chromosomal DNA replication. ${ }^{[46]}$ Although echinomycin is a cytotoxic compound, its evaluation in clinical trials has only shown marginal activity against various human cancers. ${ }^{[40]}$

\subsection{Mithramycin A and its analogs}

Mithramycin A (Figure 1) binds to CG-rich DNA tracts through the minor groove without intercalation. ${ }^{[1,9]}$ A characteristic feature of the binding to DNA is that it requires the presence of divalent cations. ${ }^{[1,47]}$ The clinical utility of mithramycin $\mathrm{A}$ as an antitumor agent is restricted by serious toxic side effects. Mithramycin A can compete with Sp1 for its putative binding sites. ${ }^{[5]}$ Indeed, it is used in experiments aimed at establishing the role of Sp1-binding sites in the control of gene expression.

Several analogs obtained by combinatorial biosynthesis show enhanced antitumor activities owing to their better cellular uptake and bioavailability. ${ }^{[48-50]}$ They are also less toxic than mithramycin A. ${ }^{[51]}$ Those mithralogs bear a diversity of modifications in the side chain attached to the C-3 of the mithramycin chromophore, which may explain their distinct DNAbinding properties, cellular uptake, and effects on gene expression. ${ }^{[48,52-55]}$ The strong effect of mithramycin A on Spl binding is enhanced in some analogs, which show improved DNAbinding properties. ${ }^{[47,53]}$ In various human ovarian cancer cells, DIG-MSK (EC-8042), one such analog, strongly inhibits the $S p 1$ gene and several Sp-responsive genes. ${ }^{[54,56]}$ EC-8042 impedes the growth of stem-like tumor cells in tumor spheroids from ERG-positive prostate cancer cells and mouse-derived tumors. ${ }^{[55]}$

Mithramycin A has been reintroduced as antitumor drug because it inhibits the EWS-FLI1 oncogenic transcription factor, suppressing the growth of two different Ewing sarcoma family of tumors and expanding the survival of mice bearing human tumor xenografts. ${ }^{[57]}$ Some analogs exhibit improved targeting of the EWS-FLI1 oncogenic transcription factor. ${ }^{[58]}$

\subsection{Plitidepsin and Lurbinectedin}

The renewed interest in small molecules that bind to DNA through the minor groove might be illustrated by the development of novel compounds such as plitidepsin and lurbinectedin, which are in clinical trials. Plitidepsin (Figure 1) is a natural molecule extracted from a marine organism, while lurbinectedin is a new synthetic alkaloid structurally related to the ecteinascidins that also originate from marine organisms. Both compounds are selective inhibitors of transactivated transcription catalyzed by RNA polymerase II, and they induce transcription-dependent replication stress. ${ }^{[59]}$ 
Lurbinectedin binds covalently to the DNA minor groove, ${ }^{[60]}$ displaying strong antitumor activity in a variety of cancer cell lines and tumor xenografts. ${ }^{[60-61]}$ It recognizes CG-rich tracts in gene promoters, inhibiting transcription. ${ }^{[59-60]}$ Also, it can irreversibly alter the transcription elongation step. ${ }^{[60]}$ Lurbinectedin induces the specific degradation of transcribing RNA polymerase II in several human tumor cell lines. ${ }^{[60]}$ It shows synergistic cytotoxic activity with doxorubicin in mice bearing human tumor xenografts. ${ }^{[62]}$

Plitidepsin blocks the transcription elongation step selectively. ${ }^{[63]}$ It has been postulated that the primary target of plitidepsin would be the eukaryotic elongation factor 1A2 (eEF1A2), which is overexpressed in numerous tumors. ${ }^{[63]}$ It shows antitumor activity against several cancers, being a potential treatment for multiple myeloma. ${ }^{[64]}$ Plitidepsin and lurbinectedin are very active against tumor cells displaying 'oncogene addiction' — cells depending on a fusion oncoprotein-. ${ }^{[61,63]}$

\section{GENOME-WIDE APPROACHES REVEAL DETAILED EFFECTS OF DNA- BINDING DRUGS ON TUMOR CELLS}

Genome-wide screening technologies permit a systematic study of genetic contributions to drug-sensitive phenotypes. ${ }^{[65]}$ They also help us reach a deeper understanding of the mode of action of DNA-binding drugs. At present, genomic analyses explore events that may influence both tumor development and therapeutic outcome thus they enable the understanding of the effects of chemotherapeutic agents in cultured cancer cells. ${ }^{[66-67]}$

\subsection{Using omic data to characterize drugs acting on DNA}

The analysis of the effects of DNA-binding drugs on a variety of human cell lines provides information on the mechanisms of drug action, ${ }^{[68-71]}$ allowing us to delineate the mechanisms of action of new anticancer compounds. ${ }^{[72]}$ Human cancer cell lines lack the complexities of a complete organism, but well-characterized cell lines have advantages in evaluating DNAbinding drugs because they are established models for cancer biology. They also permit relating DNA damage and genomic alterations to drug response. ${ }^{[9,71,73]}$ Beyond genomics, it is anticipated to observe an expansion into other aspects like proteomics and metabolomics.

Cells treated with DNA-binding drugs can be analyzed by gene expression microarrays, which in genome-wide analyses are used together with real-time PCR (qRT-PCR) and chromatin immunoprecipitation (ChIP) $\cdot^{[41,56,70,72]}$ Microarrays have been used to identify global changes in gene expression patterns in human Jurkat $\mathrm{T}$ cells in the presence of actinomycin D. ${ }^{[36]}$ Genes that showed dramatic enhancements in both mRNA and nuclear run-on RNA were abrogated by pretreatment of cells with actinomycin D, while many genes regulated only through altered mRNA turnover were resistant to the compound. ${ }^{[36]}$ 
RNA-seq (a next-generation high throughput RNA sequencing approach) is used to quantify cellular RNA, while ChIP-seq (chromatin immunoprecipitation followed by RNA sequencing) can identify overlaps and differences among the genes with altered expression after treatment. ${ }^{[74]}$

Several databases gather the effects of antitumor agents on the whole gene expression in human cell lines. ${ }^{[70]}$ They contain somehow overlapping/complementary information matching the response of cells with genomic features. ${ }^{[70-71]}$ Sometimes, these databases emphasize the effects of most of the DNA-binding drugs on the 'transcription factor network'. Those datasets provide information that improves our knowledge of the cellular response to cytotoxic compounds. The NCI-60 database under the sponsorship of the 'Developmental Therapeutics Program' has screened over 100,000 molecules from natural sources or obtained by synthetic chemistry, employing a panel of 60 different human cancer cell lines. ${ }^{[69-71]}$ It comprises the largest publicly available panel of cell lines and drugs database. ${ }^{[68,70]}$ The Cancer Cell Line Encyclopedia (CCLE) contains information from around 1450 cell lines and the pharmacological profiles for 24 anticancer drugs across 507 cell lines. ${ }^{[75-77]}$ The Genomics of Drug Sensitivity in Cancer (GDSC) combines genomics data from the Cancer Genome Project and drug activity data. ${ }^{[78]}$ It encompasses information regarding 980 cell lines and contains information about 450 compounds targeting 24 pathways. ${ }^{[70,79]} \mathrm{A}$ comparison of the transcript expression profiles of CCLE and GDSC found a high correlation between their data. ${ }^{[80]}$ Furthermore, the Cancer Genome Atlas (TCGA) molecularly characterizes around 20,000 primary cancers and matched normal specimens spanning 33 cancer types. ${ }^{[70,81]}$ Other valuable pharmacogenomics datasets are the Cancer Target Discovery and Development Project (CTD2) ${ }^{[82]}$ which aims to validate multiple targets, and the Cancer Therapeutics Response Portal (CTRP), ${ }^{[83]}$ which can be mined to acquire insights into the mechanisms of action of small compounds.

The comprehensive gene expression and drug sensitivity databases define genes whose expression shows a significant correlation to patterns of drug sensitivity. ${ }^{[68-70,79]}$ For almost any drug, sets of genes associated with its mechanisms of action can be obtained. While changes in gene expression correlate with the activity of many antitumor drugs, the expression of other genes correlates solely with drugs of comparable chemical structure or/and mechanism of action. ${ }^{[66]}$

Genome-wide data about gene expression in the presence of DNA-binding drugs are usually deposited in the GEO (Gene Expression Omnibus) dataset. ${ }^{[84]}$ This dataset can be employed to evaluate the "enrichment" in genes associated with particular biological or 
functional cell pathways as a consequence of drug treatments, by using tools such as GoMiner, ${ }^{[85]}$ PANTHER, ${ }^{[86-87]}$ or GSEA. ${ }^{[88]}$

In most cases, the different genomic analyses corroborate that drugs that share the primary mechanism of action can encompass diverse secondary mechanisms. Notwithstanding many possibilities, gene clustering of microarray data indicates a high coherence for most mechanisms of drug action, ${ }^{[68-70]}$ including the effects of DNA-binding drugs on gene expression. A correlation has been observed in the NCI-60 panel of human cells between gene expression and drug activity patterns. ${ }^{[68]}$ Average-linkage dendrograms, based on the activity patterns of 118 drugs over the 60 cell lines, formed five clusters. Among them, two related to "DNA-damaging agents" and to "topoisomerase II inhibitors", ${ }^{[68]}$ which embrace most of the paradigmatic compounds discussed above. Topoisomerase II inhibitors, excluding etoposide and teniposide, bind to DNA principally by intercalation. ${ }^{[9]}$ Remarkably, topoisomerase II inhibitors (other than etoposide) clustered in two distinct groups, one incorporating the anthracyclines and teniposide, and other containing mitomycin C (a potent DNA crosslinker) together with molecules that could produce double-strand breaks. These results highlight that molecules with the same primary mechanisms of action - as those acting on gene transcription directly - might have totally different secondary mechanisms of action. ${ }^{[68]}$

Genes involved in sensitivity to anticancer drugs have been identified through big data analyses of genome-wide studies in cultured cell lines. It is expected that any improvement in mining transcriptomic data will help us understand the complexity of gene expression in cancer and to discover new therapeutic targets. ${ }^{[89]}$ Nevertheless, our understanding of the effects of any DNA-binding drug based on genome-wide analyses is partial because the drug effects may not always be manifested at the transcriptional level. It is worth noting that the interrelation between cell cycle pathways may hinder a correct interpretation of genome-wide experiments, as it makes it difficult to differentiate between direct and indirect effects.

Figure 2 shows a gene ontology (GO-slim) analysis ${ }^{[87]}$ of the genes down-regulated after treatment of human cancer cells with either WP631 or echinomycin. ${ }^{[29,41]}$ The figure depicts the percentage of genes down-regulated that belong to different GO molecular cell function categories obtained by using PANTHER. ${ }^{[86]}$ PANTHER GO-slim annotations represent only a subset of GO annotations selected from available experimental observations. ${ }^{[87]}$ For both DNA-binding drugs, there is a significant enrichment in GO categories related to "binding" and "transcription" (see the legend to Figure 2), in keeping with the properties and mechanisms of action of those compounds. Furthermore, Tables 1 and 2 present a GOcomplete analysis of the experimental data, which were retrieved from GEO (accession number: GSE7835) and supporting Table S1. 
Similar analyses on molecular function and biological process classes performed of genes down-regulated by mithramycin A and some of its analogs indicates a prevalence of genes involved in 'transcription regulation' and 'nucleic acid metabolism', suggesting that these compounds could influence the expression of multiple transcriptional regulatory factors. ${ }^{[5,48,56]}$ Genome-wide studies confirm that mithramycin A and its analogs inhibit gene transcription, altering multiple pathways critical for tumor development. Sp1 transcription factor regulates most of the genes which expression is reduced in various cancer cell types. ${ }^{[48,56]} \mathrm{MSDK}$ and DIG-MSK (EC-8042) are two such mithralogs, which affect the expression of multiple transcriptional regulatory and co-regulatory factors, mainly of genes involved in transcription regulation and nucleic acid metabolism. ${ }^{[48,56]}$

RNA-seq analyses reveal deep changes in the transcriptome of chronic lymphocytic leukemia cells treated with the mithralog EC-7072 (MSK). ${ }^{[90]}$ They include a wide downregulation of multiple components and targets of the B-cell receptor signaling pathway. ${ }^{[90]}$

On the other hand, a genome-wide analysis of gene expression in malignant T-cells has provided evidence of differentially repressed genes upon treatment with anthracycline-based chemotherapy (consisting of cyclophosphamide, doxorubicin, vincristine, and prednisone). ${ }^{[91]}$

ChIP (chromatin immunoprecipitation) assays show that echinomycin specifically inhibits HIF-1 binding to the $V E G F$ gene promoter. ${ }^{[42]}$ These assays disclose changes in the occupancy of the HIF-responsive elements in the promoter, in keeping with the inhibition of gene transcription by echinomycin, describe above. Likewise, ChIP analyses have confirmed that several mithramycin analogs (MSK, MSDK and DIG-MSK) alter the binding of Sp1 to promoters of genes which expression is abrogated in human ovarian or prostate cancer cells. ${ }^{[56,92]}$

Chem-seq comprises chemical affinity capture followed by massively parallel sequencing. It is used to disclose the genome-wide localization of small compounds, which can render a complete description of drug-binding sites all over the genome. ${ }^{[66]}$ Chem-seq experiments have unveiled that doxorubicin enhances nucleosome turnover around gene promoters. ${ }^{[93]}$

\subsection{Drug sensitivity databases in the pursuit of precision medicine}

We can use the different pharmacogenomic databases described above for decisionmaking in personalized medical treatments. Precision medicine (P4-medicine) aims to be predictive, preventive, personalized, and participatory. It uses the advances in data generation and data modeling and seeks to select treatments using measures of gene expression and to test the therapeutic response. ${ }^{[94]}$ The clinical implementation of pharmacogenomics is a medical priority, although many of its practical applications still need to be developed. Responses of well-characterized cancer cell line panels to a variety of compounds have been used to make 
predictive models of drug activity that can be tested clinically. ${ }^{[66,71,95]}$ Translating the pharmacogenomics of cell lines into in vivo therapies requires a variety of tumor-derived cancer cell lines, genomic data, and therapeutic feedbacks, in which case drug response data can identify candidate drugs from omic data. ${ }^{[67,71]}$ Abrogating the expression of tumordeveloping genes by drugs that bind to DNA stays as a suitable therapeutic approach. Genetic variations between tumor types and among patients can be observed during tumor development, and they are documented in the various databases. The omic analysis of samples taken from patients can be complex since they receive combinations of drugs that are not the same. Indeed, identifying genomic predictors from pharmacological data has been questioned. ${ }^{[80]}$

Computing capabilities allow us to use large-scale data in P4-medicine. In particular, artificial intelligence (AI) approaches can help us identify patients who require specific antitumor treatment and provide personalized protocols for each individual. ${ }^{[67,94]}$ The pharmacological development of agents, including DNA-binding drugs, through clinical trials is rather expensive and takes several years. This makes helpful the current AI concepts of precision medicine based on computer 'machine learning'. Machine learning techniques for training and generalization from data, as well as advanced statistical methods, play an important role in the analysis of multidimensional datasets generated by new tools like the omic approaches, facilitating the easiest development of novel drugs. ${ }^{[70]}$ Nevertheless, these computational tools might not always decipher biological complexity.

Genomic measurements identify molecular signatures of tumors that have been used to classify patients according to their response to various treatments. ${ }^{[70]}$ The molecular characteristics associated with the tumor response can be discovered by comparing the clinical responses with the omic characteristics of the tumors that are susceptible, or by comparing the responses of cell lines treated with drugs with their omic features. On the other hand, the search for new active drugs focused on rational approaches to be used in P4-medicine, which is helped by AI methodologies, encompasses the development of high-performance screenings that evaluate thousands of compounds, for example, using DNA fragments consisting of consensus sequences for a transcription factor, to seek for different 'tailored' antitumor agents. ${ }^{[95]}$ Given that topoisomerases remain as therapeutic targets, antitumor agents have been developed as topoisomerase poisons in pursuing precision medicine. Recent advances in this subject are aimed at designing isoform-specific topoisomerase II poisons. ${ }^{[16]}$

A comprehensive view of the mechanisms of action of DNA-binding agents and their effects on the cellular genome is given by the diverse omic tools. The association between 
treatment with cytotoxic drugs, differences in gene transcription, and cell-killing outcome, indicates a significant interrelation among these factors to explain cytotoxicity. ${ }^{[65,89]}$

\section{TRACING THE MECHANISMS OF CELL DEATH INDUCED BY DNA-BINDING DRUGS}

It is worth considering how DNA-binding drugs, and in general antitumor therapies, may commit cancer cells to die. Those drugs could produce structural changes in DNA interfering with replication and transcription. They could also promote crosslinks and make strand breaks. Moreover, intercalating compounds distort DNA structure. ${ }^{[1,9]}$ Intercalation generates mutations, such as frame-shift ones, which might challenge DNA replication and transcription. ${ }^{[1-2,6]}$

Cells contain sensors that detect DNA damage and spread the signal to executors molecules. ${ }^{[96]}$ Many components of the signaling pathway, like the caspases, have been characterized. The p53 tumor suppressor is expressed in response to DNA damage, and it halts the cell cycle to permit DNA repair. ${ }^{[97]}$ If the repair does not work, cellular response is to induce cell death. ${ }^{[10,98]}$

However, our current knowledge does not fully explain in what way a damaged cell is committed to die. A common model postulates that during antitumor therapy cells are prompted to undergo apoptosis, thereby cells that can evade apoptosis will be resistant to such therapy. Hence, the statement is often made that the amount of cell death produced by DNA damage is related to the activation of apoptosis. Apoptosis, a well-defined program of cell death, ${ }^{[10,99]}$ is significantly influenced by the fact that in cancer many routes leading to it are either mutated or deregulated. ${ }^{[100-101]}$ Tumor cells bearing the wild-type form of p53 can undergo apoptosis, thereby the absence of wild-type p53 activity is considered a crucial predictor of failure to respond to chemotherapy. ${ }^{[100]}$ Anyway, antitumor therapy induces not only apoptosis, but other forms of cell death such as mitotic catastrophe, necrosis, and autophagy, or a permanent cell arrest with phenotype characteristics of senescence. ${ }^{[99,102]}$ Figure 3 shows a schematic summary of the different pathways and mechanisms leading to cell death in p53+/+ and p53-/- cells treated with DNA-binding drugs. Mitotic catastrophe, which results from abnormal mitosis, does not seem to depend on wild-type $\mathrm{p} 53,{ }^{[101,103]}$ thus its rise might be advantageous in cancer treatment. ${ }^{[100]}$ Mitotic catastrophe designates the presence of faulty mitosis leading to cell death, which may occur via apoptosis or necrosis. ${ }^{[101]}$ Necrosis a form of unregulated cell death - elicits a pro-inflammatory response that is not observed in apoptosis. ${ }^{[102]}$ The inflammatory response could recruit some immune cells to tumors, 
increasing the efficiency of chemotherapy. Nevertheless, an inflammatory response might also damage normal tissues, and even cause associated tumor cell metastasis.

Targeting multiple death pathways seems to be a suitable strategy to deal with tumor heterogeneity and to overcome resistance to DNA-binding drugs, while it is likely that chemotherapy using a single drug may be not sufficient to induce cancer cell death. Together with exploring the pathways that make DNA-binding compounds or other antitumor agents to commit cells to die, specific anti-cancer agents directed toward members of the cell death signaling pathways are under development. ${ }^{[104]}$

\section{FINAL COMMENTS}

Drugs that bind to DNA remain at the forefront of cancer therapy. Many of them have been evaluated in the hope of learning the rules for targeting specific DNA sequences and for controlling gene expression in tumors. Several DNA-binding drugs compete with transcription factors to bind to consensus binding sites in gene promoters, altering gene expression.

Currently, omic (genome-wide) tools are used to obtain distinctive and unbiased details about the effects of DNA-drug interactions on gene expression. They measure indirect genome readouts that can identify targets for DNA-binding molecules.

Cells treated with DNA-binding drugs can be analyzed for gene expression by using microarrays or high-throughput sequencing strategies, such as RNA-seq and ChIP-seq. Combinations of these techniques produce a comprehensive overview of the effects of DNAbinding compounds on gene expression. They might guide the development of new compounds aimed at modulating transcription more precisely. Simultaneously, the gathering of large-scale omic results in publicly accessible databases may become a driver for pharmacological decision-making in P4-medicine.

The rules governing the cell death response to damage produced by DNA-binding drugs have not been completely elucidated. A common model considers that during antitumor therapy cells are driven to undergo apoptosis, thus cells that can evade apoptosis would be resistant to such therapy. Therefore, the cytotoxicity of DNA-binding drugs is often related to the activation of apoptosis. However, in addition to apoptosis, which mainly depends on the activity of the tumor suppressor protein p53, cells can be eliminated after DNA damage by other mechanisms like necrosis or mitotic catastrophe. Targeting of multiple death pathways appears to be a suitable strategy to deal with tumor heterogeneity and to overcome resistance to some DNA-binding drugs.

\section{CONFLICT OF INTERESTS}

The author declares he has no conflict of interests. 


\section{REFERENCES}

[1] M. J. Waring, Annu. Rev. Biochem. 1981, 50, 159.

[2] M. Gniazdowski, W. A. Denny, S. M. Nelson, M. Czyz, Expert Opin. Ther. Targets 2005, $9,471$.

[3] C. Yan, P. J. Higgins, Biochim. Biophys. Acta 2013, 1835, 76.

[4] M. A. Bouhlel, M. Lambert, M. H. David-Cordonnier, Curr. Top. Med. Chem. 2015, $15,1323$.

[5] C. Vizcaíno, S. Mansilla, J. Portugal, Pharmacol. Ther. 2015, 152, 111.

[6] J. Portugal, Biochem. Pharmacol. 2018, 155, 336.

[7] L. Pett, J. A. Hartley, K. Kiakos, Curr. Top. Med. Chem. 2015, 15, 1293.

[8] M. Lambert, S. Jambon, S. Depauw, M. H. David-Cordonnier, Molecules 2018, 23, 1479.

[9] J. Portugal, F. Barceló, Curr. Med. Chem. 2016, 23, 4108.

[10] E. C. de Bruin, J. P. Medema, Cancer Treat. Rev. 2008, 34, 737.

[11] M. J. Bywater, R. B. Pearson, G. A. McArthur, R. D. Hannan, Nat. Rev. Cancer 2013, $13,299$.

[12] S. Mansilla, J. Portugal, Biochimie 2008, 90, 976.

[13] P. Thandapani, Pharmacol. Ther. 2019, 199, 129.

[14] Y. He, W. Long, Q. Liu, Front. Pharmacol. 2019, 10, 361.

[15] Y. Pommier, Y. Sun, S. N. Huang, J. L. Nitiss, Nat. Rev. Mol. Cell Biol. 2016, 17, 703.

[16] J. L. Delgado, C. M. Hsieh, N. L. Chan, H. Hiasa, Biochem. J. 2018, 475, 373.

[17] E. Salvatorelli, P. Menna, E. Cantalupo, M. Chello, E. Covino, F. I. Wolf, G. Minotti, Biochim. Biophys. Acta 2015, 1848, 2727.

[18] C. A. Frederick, L. D. Williams, G. Ughetto, G. A. van der Marel, J. H. van Boom, A. Rich, A. H. Wang, Biochemistry 1990, 29, 2538.

[19] C. C. Wu, Y. C. Li, Y. R. Wang, T. K. Li, N. L. Chan, Nucleic Acids Res. 2013, 41, 10630.

[20] G. L. Semenza, J. Clin. Invest. 2013, 123, 3664.

[21] K. Lee, D. Z. Qian, S. Rey, H. Wei, J. O. Liu, G. L. Semenza, Proc. Natl. Acad. Sci. USA 2009, 106, 2353.

[22] S. Y. Chiang, J. C. Azizkhan, T. A. Beerman, Biochemistry 1998, 37, 3109.

[23] J. B. Chaires, F. F. Leng, T. Przewloka, I. Fokt, Y. H. Ling, R. Perez-Soler, W. Priebe, J. Med. Chem. 1997, 40, 261.

[24] W. Priebe, I. Fokt, T. Przewloka, J. B. Chaires, J. Portugal, J. O. Trent, Methods Enzymol. 2001, 340, 529.

[25] J. Portugal, D. J. Cashman, J. O. Trent, N. Ferrer-Miralles, T. Przewloka, I. Fokt, W. Priebe, J. B. Chaires, J. Med. Chem. 2005, 48, 8209.

[26] S. Villamarín, S. Mansilla, N. Ferrer-Miralles, W. Priebe, J. Portugal, Eur. J. Biochem. 2003, $270,764$.

[27] B. Martín, A. Vaquero, W. Priebe, J. Portugal, Nucleic Acids Res. 1999, 27, 3402.

[28] S. Mansilla, W. Priebe, J. Portugal, Biochemistry 2004, 43, 7584.

[29] S. Mansilla, W. Priebe, J. Portugal, Eur. J. Pharmacol. 2006, 540, 34.

[30] S. Mansilla, M. Rojas, M. Bataller, W. Priebe, J. Portugal, Biochem. Pharmacol. 2007, $73,934$.

[31] R. R. Nair, H. Wang, M. S. Jamaluddin, I. Fokt, W. Priebe, D. D. Boyd, Oncol. Res. 2005, 15, 265.

[32] R. A. Grimm, H. B. Muss, D. R. White, F. Richards, 2nd, M. R. Cooper, J. J. Stuart, D. V. Jackson, P. L. Barnes, C. L. Spurr, Cancer Chemother. Pharmacol. 1980, 4, 195.

[33] M. Malogolowkin, C. A. Cotton, D. M. Green, N. E. Breslow, E. Perlman, J. Miser, M. L. Ritchey, P. R. Thomas, P. E. Grundy, G. J. D'Angio, J. B. Beckwith, R. C. Shamberger, G. 
M. Haase, M. Donaldson, R. Weetman, M. J. Coppes, P. Shearer, P. Coccia, M. Kletzel, R. Macklis, G. Tomlinson, V. Huff, R. Newbury, D. Weeks, Pediatr. Blood Cancer 2008, 50, 236. [34] S. Kamitori, F. Takusagawa, J. Mol. Biol. 1992, 225, 445.

[35] M. C. Fletcher, K. R. Fox, Eur. J. Biochem. 1996, 237, 164.

[36] C. Cheadle, J. Fan, Y. S. Cho-Chung, T. Werner, J. Ray, L. Do, M. Gorospe, K. G. Becker, BMC Genomics 2005, 6, 75.

[37] K. Deacon, D. Onion, R. Kumari, S. A. Watson, A. J. Knox, J. Biol. Chem. 2012, 287, 39967.

[38] A. Vaquero, J. Portugal, Eur. J. Biochem. 1998, 251, 435.

[39] M. J. Waring, L. P. Wakelin, Nature 1974, 252, 653.

[40] M. J. Waring, in Molecular Aspects of Anticancer Drug-DNA Interactions (Eds: S. Neidle; M. Waring) MacMillan, London.1993; Vol. 1, p 213.

[41] N. G. Nickols, C. S. Jacobs, M. E. Farkas, P. B. Dervan, ACS Chem. Biol. 2007, 2, 561.

[42] D. Kong, E. J. Park, A. G. Stephen, M. Calvani, J. H. Cardellina, A. Monks, R. J. Fisher, R. H. Shoemaker, G. Melillo, Cancer Res. 2005, 65, 9047.

[43] B. Vlaminck, S. Toffoli, B. Ghislain, C. Demazy, M. Raes, C. Michiels, FEBS J. 2007, $274,5533$.

[44] J. Yamaguchi, T. Tanaka, H. Saito, S. Nomura, H. Aburatani, H. Waki, T. Kadowaki, M. Nangaku, Sci. Rep. 2017, 7, 6516.

[45] Y. Wang, Y. Liu, F. Tang, K. M. Bernot, R. Schore, G. Marcucci, M. A. Caligiuri, P. Zheng, Y. Liu, Blood 2014, 124, 1127.

[46] L. G. May, M. A. Madine, M. J. Waring, Nucleic Acids Res. 2004, 32, 65.

[47] F. Barceló, C. Scotta, M. Ortiz-Lombardía, C. Méndez, J. A. Salas, J. Portugal, Nucleic Acids Res. 2007, 35, 2215.

[48] V. Albertini, A. Jain, S. Vignati, S. Napoli, A. Rinaldi, I. Kwee, M. Nur-e-Alam, J. Bergant, F. Bertoni, G. M. Carbone, J. Rohr, C. V. Catapano, Nucleic Acids Res. 2006, 34, 1721.

[49] S. Previdi, A. Malek, V. Albertini, C. Riva, C. Capella, M. Broggini, G. M. Carbone, J. Rohr, C. V. Catapano, Gynecol. Oncol. 2010, 118, 182.

[50] C. Vizcaíno, S. Mansilla, L. E. Núñez, C. Méndez, J. A. Salas, F. Morís, J. Portugal, Biochem. Pharmacol. 2012, 84, 1133.

[51] L. E. Núñez, S. E. Nybo, J. González-Sabín, M. Pérez, N. Menéndez, A. F. Braña, M. He, F. Morís, J. A. Salas, J. Rohr, C. Méndez, J. Med. Chem. 2012, 55, 5813.

[52] M. Bataller, C. Méndez, J. A. Salas, J. Portugal, Mol. Cancer Ther. 2008, 7, 2988.

[53] F. Barceló, M. Ortiz-Lombardía, M. Martorell, M. Oliver, C. Méndez, J. A. Salas, J. Portugal, Biochemistry 2010, 49, 10543.

[54] A. Fernández-Guizán, S. Mansilla, F. Barceló, C. Vizcaíno, L. E. Núñez, F. Morís, S. González, J. Portugal, Chem. Biol. Interact. 2014, 219, 123.

[55] D. Shinde, D. Albino, M. Zoma, A. Mutti, S. N. Mapelli, G. Civenni, A. Kokanovic, J. Merulla, J. Pérez-Escuredo, P. Costales, F. Moris, C. V. Catapano, G. M. Carbone, Eur. Urol. Oncol. 2019, 2, 415.

[56] C. Vizcaíno, L. E. Nuñez, F. Morís, J. Portugal, PLoS One 2014, 9, e104687.

[57] P. J. Grohar, G. M. Woldemichael, L. B. Griffin, A. Mendoza, Q. R. Chen, C. Yeung, D. G. Currier, S. Davis, C. Khanna, J. Khan, J. B. McMahon, L. J. Helman, J. Natl. Cancer Inst. 2011, 103, 962.

[58] C. L. Osgood, N. Maloney, C. G. Kidd, S. Kitchen-Goosen, L. Segars, M. Gebregiorgis, G. M. Woldemichael, M. He, S. Sankar, S. L. Lessnick, M. Kang, M. Smith, L. Turner, Z. B. Madaj, M. E. Winn, L. E. Núñez, J. Gonzalez-Sabin, L. J. Helman, F. Moris, P. J. Grohar, Clin. Cancer Res. 2016, 22, 4105.

[59] E. Tumini, E. Herrera-Moyano, M. San Martin-Alonso, S. Barroso, C. M. Galmarini, A. Aguilera, Mol. Cancer Res. 2019, 17, 773. 
[60] G. Santamaría Nuñez, C. M. Robles, C. Giraudon, J. F. Martínez-Leal, E. Compe, F. Coin, P. Avilés, C. M. Galmarini, J. M. Egly, Mol. Cancer Ther. 2016, 15, 2399.

[61] E. Yokoi, S. Mabuchi, K. Shimura, N. Komura, K. Kozasa, H. Kuroda, R. Takahashi, T. Sasano, M. Kawano, Y. Matsumoto, M. Kodama, K. Hashimoto, K. Sawada, T. Kimura, Invest. New Drugs 2019, 37, 818.

[62] E. Calvo, V. Moreno, M. Flynn, E. Holgado, M. E. Olmedo, M. P. López Criado, C. Kahatt, J. A. López-Vilarino, M. Siguero, C. Fernández-Teruel, M. Cullell-Young, A. Soto Matos-Pita, M. Forster, Ann. Oncol. 2017, 28, 2559.

[63] A. Losada, M. J. Muñoz-Alonso, C. Garcia, P. A. Sánchez-Murcia, J. F. Martinez-Leal, J. M. Dominguez, M. P. Lillo, F. Gago, C. M. Galmarini, Sci. Rep. 2016, 6, 35100.

[64] M. Leisch, A. Egle, R. Greil, Future Oncol. 2019, 15, 109.

[65] N. M. Gerhards, S. Rottenberg, Drug Resist. Updat. 2018, 36, 30.

[66] R. Rodriguez, K. M. Miller, Nat. Rev. Genet. 2014, 15, 783.

[67] J. D. Mannheimer, D. L. Duval, A. Prasad, D. L. Gustafson, BMC Med. Genomics 2019, $12,87$.

[68] U. Scherf, D. T. Ross, M. Waltham, L. H. Smith, J. K. Lee, L. Tanabe, K. W. Kohn, W. C. Reinhold, T. G. Myers, D. T. Andrews, D. A. Scudiero, M. B. Eisen, E. A. Sausville, Y. Pommier, D. Botstein, P. O. Brown, J. N. Weinstein, Nat. Genet. 2000, 24, 236.

[69] N. Nakatsu, Y. Yoshida, K. Yamazaki, T. Nakamura, S. Dan, Y. Fukui, T. Yamori, Mol. Cancer Ther. 2005, 4, 399.

[70] W. C. Reinhold, S. Varma, V. N. Rajapakse, A. Luna, F. G. Sousa, K. W. Kohn, Y. G. Pommier, Hum. Genet. 2015, 134, 3.

[71] A. Goodspeed, L. M. Heiser, J. W. Gray, J. C. Costello, Mol Cancer Res 2016, 14, 3.

[72] S. M. Nijman, Nat. Chem. Biol. 2015, 11, 942.

[73] B. Piña, D. Raldúa, C. Barata, J. Portugal, L. Navarro-Martín, R. Martínez, I. Fuertes, M. Casado, In Comprehensive Analytical Chemistry, Elsevier, Amsterdam.2018; Vol. 82, p 583.

[74] K. O. Mutz, A. Heilkenbrinker, M. Lonne, J. G. Walter, F. Stahl, Curr. Opin. Biotechnol. 2013, 24, 22.

[75] J. Barretina, G. Caponigro, N. Stransky, K. Venkatesan, A. A. Margolin, S. Kim, C. J. Wilson, J. Lehar, G. V. Kryukov, D. Sonkin, A. Reddy, M. Liu, L. Murray, M. F. Berger, J. E. Monahan, P. Morais, J. Meltzer, A. Korejwa, J. Jane-Valbuena, F. A. Mapa, J. Thibault, E. Bric-Furlong, P. Raman, A. Shipway, I. H. Engels, J. Cheng, G. K. Yu, J. Yu, P. Aspesi, Jr., M. de Silva, K. Jagtap, M. D. Jones, L. Wang, C. Hatton, E. Palescandolo, S. Gupta, S. Mahan, C. Sougnez, R. C. Onofrio, T. Liefeld, L. MacConaill, W. Winckler, M. Reich, N. Li, J. P. Mesirov, S. B. Gabriel, G. Getz, K. Ardlie, V. Chan, V. E. Myer, B. L. Weber, J. Porter, M. Warmuth, P. Finan, J. L. Harris, M. Meyerson, T. R. Golub, M. P. Morrissey, W. R. Sellers, R. Schlegel, L. A. Garraway, Nature 2012, 483, 603.

[76] National Cancer Institute cell line panel (NCI-60).

https://dtp.cancer.gov/discovery_development/nci-60/ (accessed January 2020).

[77] Cancer Cell Line Encyclopedia (CCLE). https://portals.broadinstitute.org/ccle (accessed January 2020).

[78] Genomics of Drug Sensitivity in Cancer (GDSC) https://www.cancerrxgene.org (accessed January 2020).

[79] M. J. Garnett, E. J. Edelman, S. J. Heidorn, C. D. Greenman, A. Dastur, K. W. Lau, P. Greninger, I. R. Thompson, X. Luo, J. Soares, Q. Liu, F. Iorio, D. Surdez, L. Chen, R. J. Milano, G. R. Bignell, A. T. Tam, H. Davies, J. A. Stevenson, S. Barthorpe, S. R. Lutz, F. Kogera, K. Lawrence, A. McLaren-Douglas, X. Mitropoulos, T. Mironenko, H. Thi, L. Richardson, W. Zhou, F. Jewitt, T. Zhang, P. O'Brien, J. L. Boisvert, S. Price, W. Hur, W. Yang, X. Deng, A. Butler, H. G. Choi, J. W. Chang, J. Baselga, I. Stamenkovic, J. A. Engelman, S. V. Sharma, O. Delattre, J. Saez-Rodriguez, N. S. Gray, J. Settleman, P. A. 
Futreal, D. A. Haber, M. R. Stratton, S. Ramaswamy, U. McDermott, C. H. Benes, Nature 2012, 483, 570.

[80] B. Haibe-Kains, N. El-Hachem, N. J. Birkbak, A. C. Jin, A. H. Beck, H. J. Aerts, J. Quackenbush, Nature 2013, 504, 389.

[81] Cancer Genome Atlas (TCGA). https://cancergenome.nih.gov/ (accessed January 2020).

[82] Cancer Target Discovery and Development Project (CTD2)

https://ocg.cancer.gov/programs/ctd2 (accessed January 2020).

[83] Cancer Therapeutics Response Portal (CTRP). https://portals.broadinstitute.org/ctrp/ (accessed January 2020).

[84] Gene Expression Omnibus (GEO). https:// www.ncbi.nlm.nih.gov/geo/ (accessed January 2020).

[85] GoMiner. https://discover.nci.nih.gov/gominer/index.jsp (accessed January 2020).

[86] Protein Analysis Through Evolutionary Relationships (PANTHER).

http://pantherdb.org (accessed January 2020).

[87] H. Mi, A. Muruganujan, D. Ebert, X. Huang, P. D. Thomas, Nucleic Acids Res. 2019, 47, D419.

[88] Gene Set Enrichment Analysis (GSEA).

http://software.broadinstitute.org/gsea/index.jsp (accessed January 2020).

[89] Y. Xiang, Y. Ye, Z. Zhang, L. Han, Trends Cancer 2018, 4, 823.

[90] S. Lorenzo-Herrero, C. Sordo-Bahamonde, G. Bretones, A. R. Payer, A. P. González-

Rodriguez, E. González-Garcia, J. Pérez-Escuredo, M. Villa-Alvarez, L. E. Nuñez, F. Moris, S. González, A. López-Soto, Front. Immunol. 2019, 10, 2455.

[91] M. Magni, G. Biancon, S. Rizzitano, A. Cavane, C. Paolizzi, M. Dugo, P. Corradini, C. Carniti, Br. J. Cancer 2019, 121, 567.

[92] A. Malek, L. E. Núñez, M. Magistri, L. Brambilla, S. Jovic, G. M. Carbone, F. Moris,

C. V. Catapano, PLoS One 2012, 7, e35130.

[93] F. Yang, C. J. Kemp, S. Henikoff, Curr. Biol. 2013, 23, 782.

[94] F. Carrasco-Ramiro, R. Peiro-Pastor, B. Aguado, Gene Ther. 2017, 24, 551.

[95] P. Jiang, W. Lee, X. Li, C. Johnson, J. S. Liu, M. Brown, J. C. Aster, X. S. Liu, Cell

Syst. 2018, 6, 343.

[96] W. P. Roos, A. D. Thomas, B. Kaina, Nat. Rev. Cancer 2016, 16, 20.

[97] T. Ho, B. X. Tan, D. Lane, Int. J. Mol. Sci. 2020, 21, 13.

[98] J. Portugal, M. Bataller, S. Mansilla, Tumori 2009, 95, 409.

[99] O. Surova, B. Zhivotovsky, Oncogene 2013, 32, 3789.

[100] J. M. Brown, L. D. Attardi, Nat. Rev. Cancer 2005, 5, 231.

[101] J. Portugal, S. Mansilla, M. Bataller, Curr. Pharm. Des. 2010, 16, 69.

[102] I. B. Roninson, E. V. Broude, B.-D. Chang, Drug Resist. Updat. 2001, 4, 303.

[103] S. Mansilla, W. Priebe, J. Portugal, Cell Cycle 2006, 5, 53.

[104] L. D. Walensky, Nat. Chem. Biol. 2019, 15, 657. 


\section{LEGENDS TO FIGURES}

FIGURE 1. Structural formulae of several DNA-binding drugs cited in the main text.

FIGURE 2. Gene ontology (GO-slim) molecular function categories which describe activities of two DNA-binding drugs at the molecular level. The figure displays the GO-slim categories, ${ }^{[87]}$ and the percentage of genes significantly $(\mathrm{p}<0.05)$ down-regulated. The analysis was performed online using PANTHER 14.1. (A) Effects of bisanthracycline WP631 in Jurkat T lymphocytes measured by using an Oncogene and Tumor Suppressor Macroarray (BD Clontech). (B) Effects of echinomycin in U251 glioblastoma cells stimulated with deferoxamine (hypoxic conditions) measured by using an Affymetrix Human Genome U133 Plus 2.0 Array. Down-regulated genes were either taken from supporting Table S1 for WP631 -see also Ref. [29]-, or retrieved from publicly available data (Gene Expression Omnibus (GEO) accession number GSE7835) for echinomycin. The GO-slim categories are subclassified, left to right, for the most represented categories in cells treated with each compound. The different categories are as follows: binding (GO:0005488), catalytic activity (GO:0003824), molecular transducer activity (GO:0060089), molecular function regulator (GO:0098772), transcription regulator activity (GO:0140110), heterocyclic compound binding (GO:1901363), chromatin binding (GO:0003682), protein binding (GO:0005515), transcription coregulator activity (GO:0003712), DNA-binding transcription factor activity (GO:0003700), molecular function regulator (GO:0098772), structural molecule activity (GO:0005198) and transporter activity (GO:0005215). Moreover, the central diagram in panel B encompasses under "Other" the following GO sub-categories: organic cyclic compound binding (GO:0097159), drug binding (GO:0008144), protein-containing complex binding (GO:0044877), amide binding (GO:0033218), ion binding (GO:0043167), small molecule binding (GO:0036094) and cofactor binding (GO:0048037).

FIGURE 3. Schematic view of the pathways leading to cell death after treatment with DNAbinding drugs. (A) Cell death pathways triggered in wild-type $\mathrm{p} 53^{(++)}$cells after treatment. (B) Cell death pathways triggered in mutant $\mathrm{p} 53^{(-/)}$cells after treatment. The figure is based on previously published ones, ${ }^{[98]}$ reproduced with permission. 
Table 1. Gene Ontology (GO) molecular function categories affected by WP631 in Jurkat T lymphocytes.

\begin{tabular}{|c|c|c|c|c|}
\hline GO categories & $\begin{array}{c}\text { Homo } \\
\text { sapiens } \\
\text { (Ref. list) }\end{array}$ & $\begin{array}{c}\text { Regulated } \\
\text { genes }\end{array}$ & $\begin{array}{c}\text { Fold } \\
\text { enrichment }\end{array}$ & $p$-value ${ }^{\mathrm{a}}$ \\
\hline \multicolumn{5}{|l|}{ Down-regulated genes } \\
\hline transcription factor binding (GO:0008134) & 689 & 7 & 6.42 & $8.61 \mathrm{E}-05$ \\
\hline RNA polymerase II-specific DNA-binding transcription factor binding (GO:0061629) & 287 & 5 & 11.01 & $8.50 \mathrm{E}-05$ \\
\hline DNA-binding transcription factor binding (GO:0140297) & 369 & 6 & 10.27 & $2.26 \mathrm{E}-05$ \\
\hline nuclear hormone receptor binding (GO:0035257) & 158 & 5 & 20.00 & 4.97E-06 \\
\hline hormone receptor binding (GO:0051427) & 191 & 5 & 16.54 & $1.24 \mathrm{E}-05$ \\
\hline chromatin binding (GO:0003682) & 566 & 6 & 6.70 & $2.36 \mathrm{E}-04$ \\
\hline double-stranded DNA binding (GO:0003690) & 1029 & 8 & 4.91 & $1.60 \mathrm{E}-04$ \\
\hline protein-containing complex binding (GO:0044877) & 1252 & 9 & 4.54 & $1.04 \mathrm{E}-04$ \\
\hline enzyme binding (GO:0019899) & 2259 & 13 & 3.64 & $1.97 \mathrm{E}-05$ \\
\hline protein binding (GO:0005515) & 12129 & 30 & 1.56 & $4.00 \mathrm{E}-05$ \\
\hline nuclear receptor binding (GO:0016922) & 115 & 5 & 27.47 & $1.06 \mathrm{E}-06$ \\
\hline protein tyrosine kinase activity (GO:0004713) & 144 & 6 & 26.33 & $1.02 \mathrm{E}-07$ \\
\hline \multicolumn{5}{|l|}{ Up-regulated genes } \\
\hline non-membrane spanning protein tyrosine kinase activity (GO:0004715) & 46 & 3 & 41.21 & $5.57 \mathrm{E}-05$ \\
\hline transmembrane receptor protein tyrosine kinase activity (GO:0004714) & 64 & 3 & 29.62 & $1.47 \mathrm{E}-04$ \\
\hline nuclear receptor binding (GO:0016922) & 115 & 5 & 27.47 & $1.06 \mathrm{E}-06$ \\
\hline protein tyrosine kinase activity (GO:0004713) & 144 & 6 & 26.33 & $1.02 \mathrm{E}-07$ \\
\hline virus receptor activity (GO:0001618) & 74 & 3 & 25.62 & $2.25 \mathrm{E}-04$ \\
\hline exogenous protein binding (GO:0140272) & 75 & 3 & 25.27 & $2.34 \mathrm{E}-04$ \\
\hline nuclear hormone receptor binding (GO:0035257) & 158 & 5 & 20.00 & 4.97E-06 \\
\hline hormone receptor binding (GO:0051427) & 191 & 5 & 16.54 & $1.24 \mathrm{E}-05$ \\
\hline RNA polymerase II-specific DNA-binding transcription factor binding (GO:0061629) & 287 & 5 & 11.01 & $8.50 \mathrm{E}-05$ \\
\hline
\end{tabular}

\footnotetext{
${ }^{a}$ Binomial test with False Discovery Rate correction.
} 
Table 2. Gene Ontology (GO) molecular function categories affected by echinomycin in U251 glioblastoma cells under hypoxic conditions. ${ }^{\text {a }}$

\begin{tabular}{|c|c|c|c|c|}
\hline GO categories & $\begin{array}{c}\text { Homo } \\
\text { sapiens } \\
\text { (Ref. list) }\end{array}$ & $\begin{array}{c}\text { Regulated } \\
\text { genes }\end{array}$ & $\begin{array}{c}\text { Fold } \\
\text { enrichment }\end{array}$ & $p$-value ${ }^{\mathrm{b}}$ \\
\hline \multicolumn{5}{|l|}{ Down-regulated genes } \\
\hline ubiquitin conjugating enzyme binding (GO:0031624) & 32 & 26 & 2.08 & $5.64 \mathrm{E}-04$ \\
\hline histone acetyltransferase activity (GO:0004402) & 61 & 45 & 1.89 & $7.16 \mathrm{E}-05$ \\
\hline ligand-actsivated transcription factor activity (GO:0098531) & 49 & 35 & 1.83 & 7.31E-04 \\
\hline methylated histone binding (GO:0035064) & 66 & 46 & 1.78 & $2.10 \mathrm{E}-04$ \\
\hline nuclear receptor binding (GO:0016922) & 115 & 80 & 1.78 & $1.48 \mathrm{E}-06$ \\
\hline transcription cofactor binding (GO:0001221) & 49 & 34 & 1.77 & $1.38 \mathrm{E}-03$ \\
\hline RNA polymerase binding (GO:0070063) & 65 & 44 & 1.73 & 5.09E-04 \\
\hline histone binding (GO:0042393) & 203 & 136 & 1.71 & 4.21E-09 \\
\hline RNA polymerase II activating transcription factor binding (GO:0001102) & 54 & 36 & 1.70 & $1.97 \mathrm{E}-03$ \\
\hline hormone receptor binding (GO:0051427) & 191 & 127 & 1.70 & $2.01 \mathrm{E}-08$ \\
\hline transcription corepressor activity (GO:0003714) & 249 & 164 & 1.68 & $3.79 \mathrm{E}-10$ \\
\hline RNA polymerase II-specific DNA-binding transcription factor binding (GO:0061629) & 287 & 189 & 1.68 & $1.85 \mathrm{E}-11$ \\
\hline DNA-binding transcription factor binding (GO:0140297) & 369 & 235 & 1.63 & $1.73 \mathrm{E}-12$ \\
\hline chromatin binding (GO:0003682) & 566 & 350 & 1.58 & $3.63 \mathrm{E}-16$ \\
\hline transcription factor binding (GO:0008134) & 689 & 420 & 1.56 & $3.61 \mathrm{E}-18$ \\
\hline DNA-binding transcription factor activity (GO:0003700) & 1337 & 796 & 1.52 & 7.32E-31 \\
\hline transcription regulator activity (GO:0140110) & 1753 & 1041 & 1.52 & $2.73 \mathrm{E}-40$ \\
\hline protein kinase activity (GO:0004672) & 618 & 364 & 1.51 & $6.11 \mathrm{E}-14$ \\
\hline DNA binding (GO:0003677) & 2523 & 1478 & 1.50 & $1.35 \mathrm{E}-55$ \\
\hline \multicolumn{5}{|l|}{ Up-regulated genes } \\
\hline small molecule binding (GO:0036094) & 2583 & 117 & 1.46 & $2.22 \mathrm{E}-05$ \\
\hline catalytic activity (GO:0003824) & 5829 & 242 & 1.33 & $1.60 \mathrm{E}-07$ \\
\hline protein binding (GO:0005515) & 12129 & 439 & 1.16 & 4.38E-07 \\
\hline binding (GO:0005488) & 15295 & 531 & 1.12 & $2.58 \mathrm{E}-07$ \\
\hline
\end{tabular}

\footnotetext{
${ }^{a}$ Echinomycin-treated U251 cells stimulated with deferoxamine

b Binomial test with False Discovery Rate correction
} 

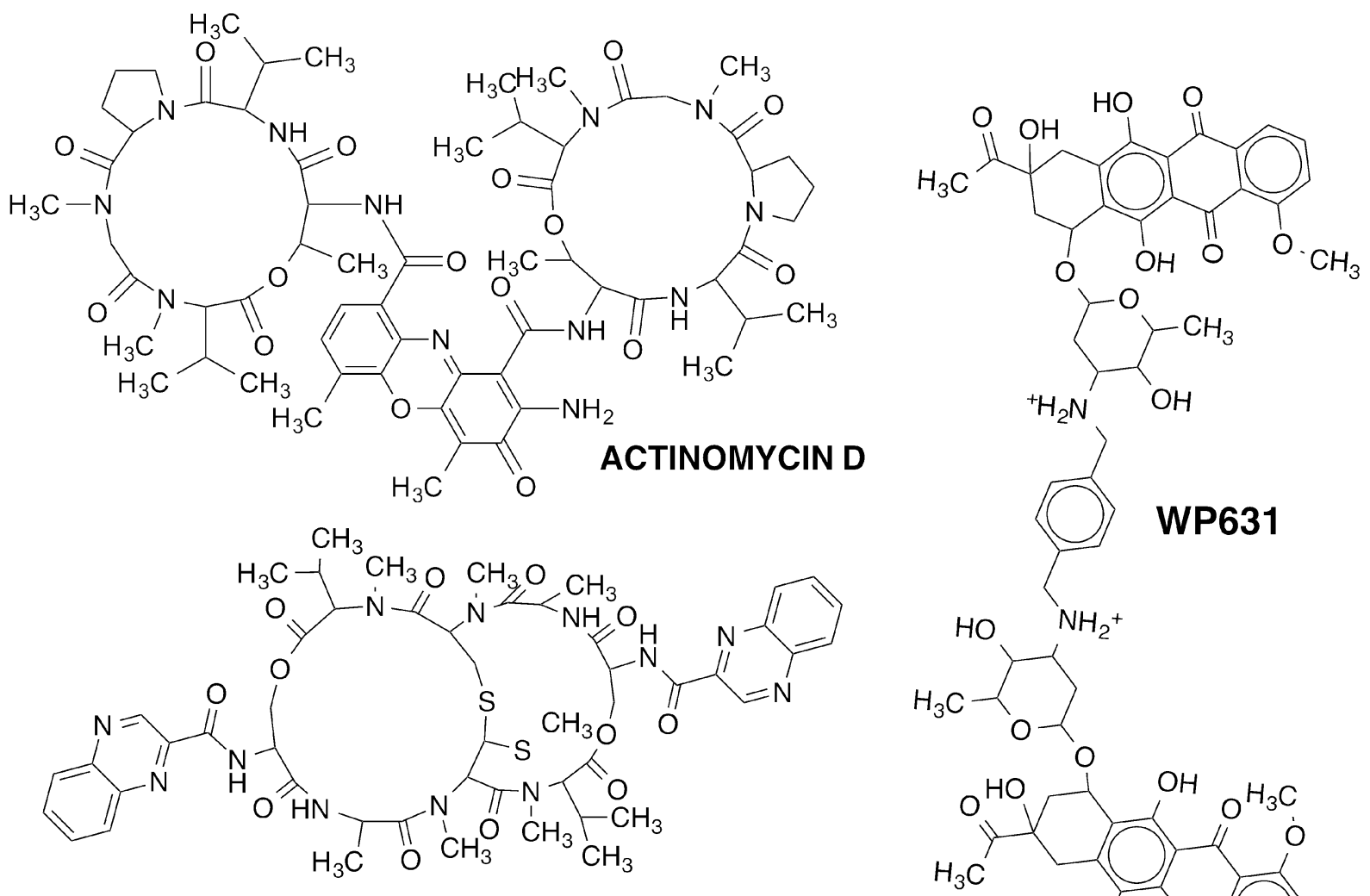

ECHINOMYCIN
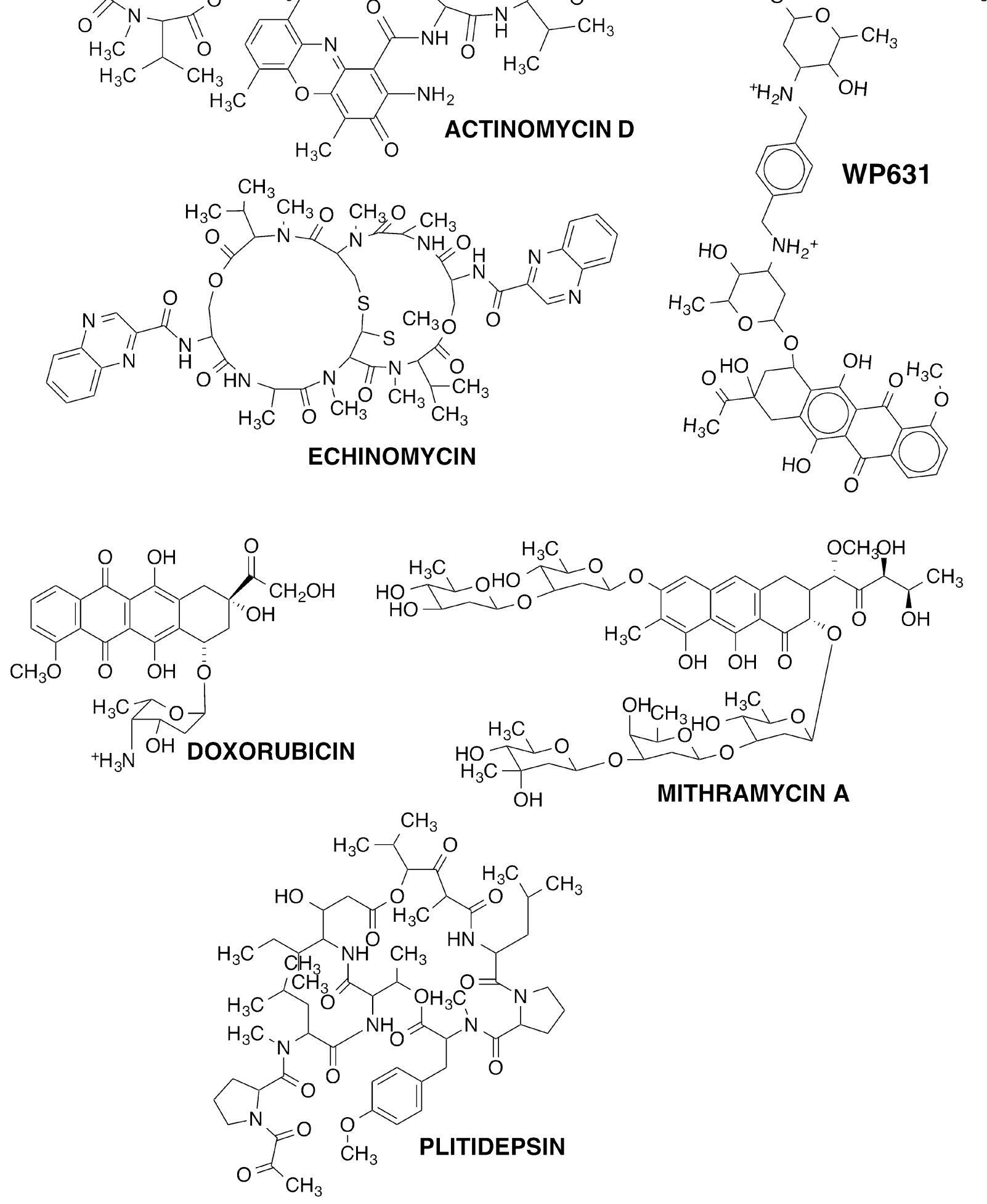
A
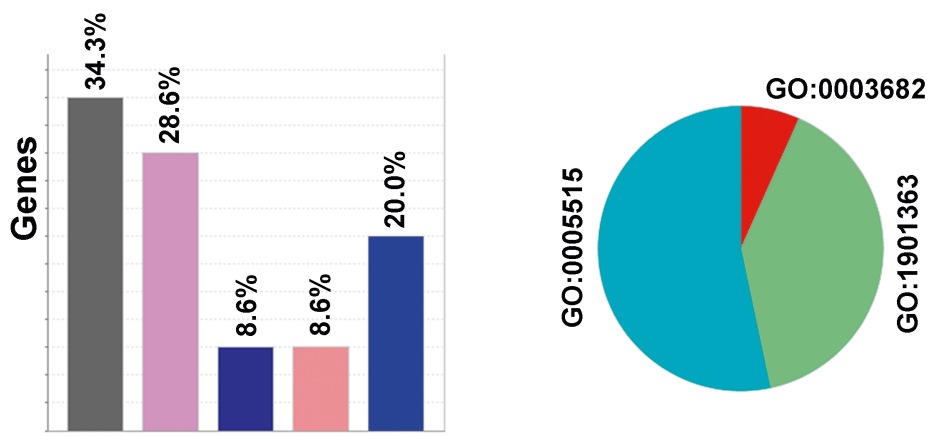

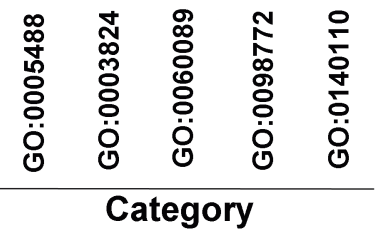

B
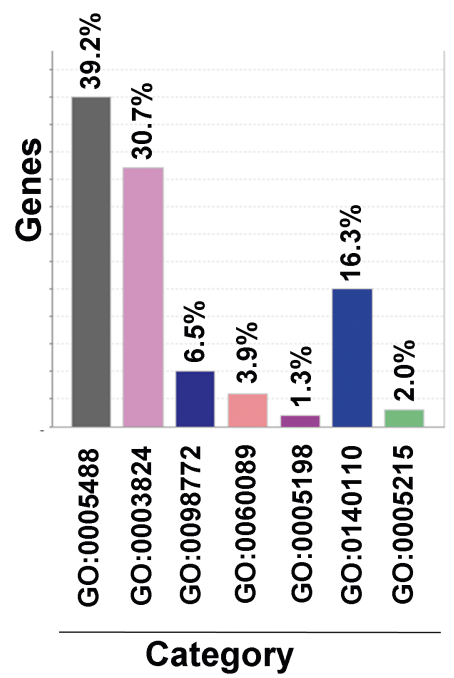

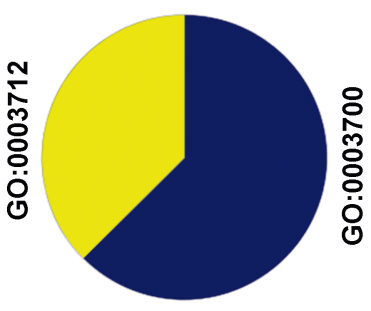

Transcription regulator activity (GO:0140110)

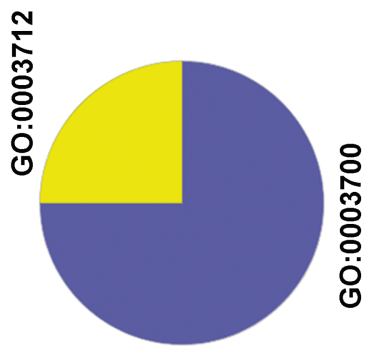

Transcription regulator activity (GO:0140110) 
A

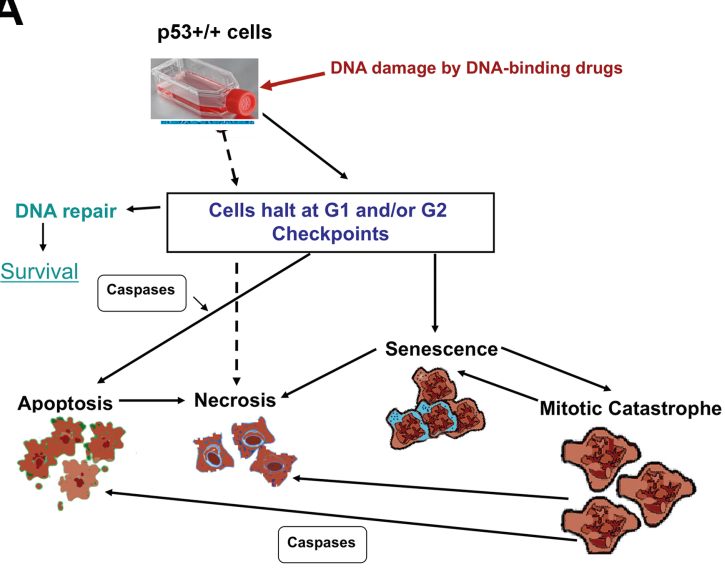

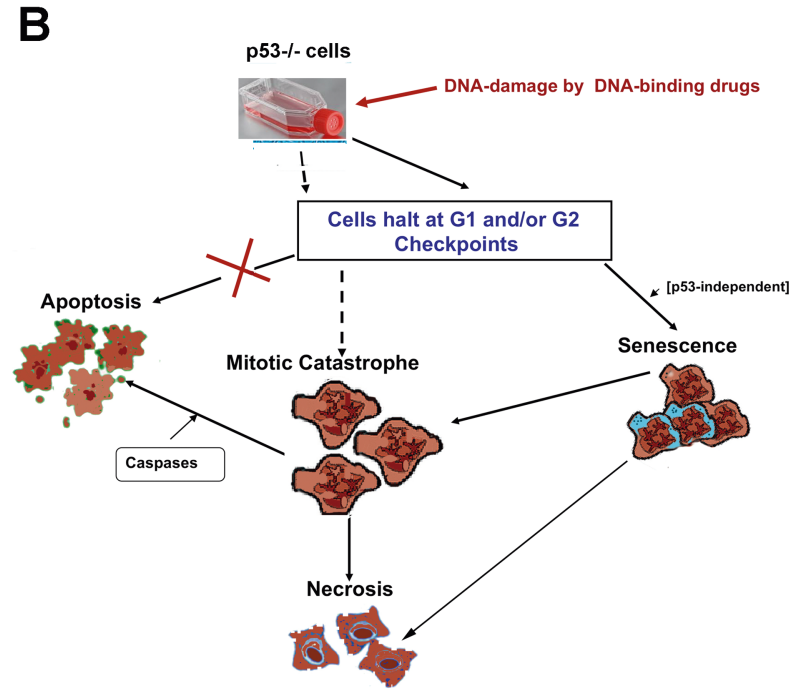

